\title{
Later Chronotype Correlates With Severe Depression in Indonesian College Students
}

\author{
Alva Supit, MD, DipClinRes ${ }^{1}$, Merry Gosal, BPH ${ }^{1}$, Prycilia Mamuaja, MD, MSc ${ }^{1}$, \\ Sicilia Kumaat, MD, $\mathrm{MPH}^{2}$, Achmad Paturusi, $\mathrm{PhD}^{1}$ \\ 'Department of Public Health, Manado State University, Tondano, Indonesia \\ ${ }^{2}$ Ministry of Health, Manado, Indonesia
}

Received: June 16, 2021

Revised: November 9, 202

Accepted: December 16, 2021

Correspondence

Alva Supit, MD, DipClinRes

Department of Public Health,

Manado State University,

Jl. Kampus Unima, Kelurahan Tounsaru,

Kecamatan Tondano Selatan 95618, Indonesia

Tel $+62-82187651891$

Fax +62-431322857

E-mail alva.supit@unima.ac.id

ORCID

Alva Supit

https://orcid.org/0000-0002-4359-4844

Merry Gosal

https://orcid.org/0000-0002-2643-0450

Prycilia Mamuaja

https://orcid.org/0000-0003-4582-8189

Sicilia Kumaat

https://orcid.org/0000-0002-1634-3767

Achmad Paturusi

https://orcid.org/0000-0003-2849-5511

@ This is an Open Access article distributed under the terms of the Creative Commons Attribution Non-Commercial License (https://creativecommons.org/licenses/by-nc/4.0) which permits unrestricted non-commercial use, distribution, and reproduction in any medium, provided the original work is properly cited.
Background and Objective The correlation between late chronotype and depression has been well documented, but reports from the equatorial area, where the sun shines throughout the year with less seasonal variation, are limited. In the present research study, we sought to 1) examine the relationship between the chronotype and mental health symptoms in an Indonesian student population and 2) explore the characteristics of those who lie at the extreme chronotype and psychometry.

Methods This is a cross-sectional questionnaire-based study including undergraduate students in an Indonesian university $(\mathrm{n}=493)$. We used the Munich Chronotype Questionnaires and the Depression, Anxiety, and Stress Scale to assess the chronotype and mental symptoms, respectively. Following this, a follow-up with an in-depth interview on the selected population at the extreme end of the chronotype was performed as an exploratory approach to identify their common characteristics.

Results Among the tested parameters, the depression score was significantly associated with chronotype ( $p=0.003)$, replicating previous findings from other areas with higher latitudes. The correlation persisted when males and females were analyzed separately $(\mathrm{p}=0.008$ and 0.037 , respectively). A follow-up qualitative analysis revealed a potential subclinical, unrealized depression among the subjects; our findings revealed the use of smartphones during or before bedtime as a common factor among those with later chronotypes.

Conclusions There is a correlation between depression score and chronotype among Indonesian college students, where subjects with later chronotype are more likely to have a higher depression score.

Sleep Med Res 2021;12(2):133-139

Keywords Chronotype; Depression; Tropical; Equatorial; Smartphone.

\section{INTRODUCTION}

Most, if not all of the living creatures on the earth perform their activities based on the daynight cycle: circa diem, which literally means 'around one day', and from which the term 'circadian' was derived $[1,2]$. In fact, $-43 \%$ of protein-coding genes in mammals are expressed in a circadian manner [3]. Thus, the circadian rhythm is not merely a biological phenomenon interesting for scientific exploration, but might be playing more roles than previously thought. Unfortunately, in the modern society, where humans are becoming more independent of the sunlight and increasingly ignoring natural circadian cues, the circadian rhythm could be the Achilles' heels that we are consistently attacking. The circadian rhythms are regulated by the suprachiasmatic nucleus (SCN) of the hypothalamus upon the daylight illumination signal from the retina. The SCN controls the sleep-wake temporal cycle, as well as all the diurnal physiological functions, such as hormone secretion and autonomic functions [4]. Chronotype, which is the natural inclination of the body to sleep at a certain time, is closely related to circadian rhythm. 
There are different types of chronotypes that reflect varying individual intrinsic synchronization responses to stimulus changes over the day.

Since humans have evolved under a robust day-night cycle with the sunlight as the main cue, the introduction of artificial light emitted by electric illuminations may shift the internal clock, and in turn, induce changes in human physiology [5]. In particular, youths and students are at a greater risk of having a disrupted circadian rhythm, as reflected by their later chronotype, i.e. sleep later at night and wake up later in the morning [6]. It has been well established that later chronotype is associated with a range of psychopathologies, including depression, substance abuse, and suicidal behavior [7-9]. However, most of the chronotype studies have been conducted in high-latitude regions where the daylight length varies across seasons [10]. In tropical countries, where around $40 \%$ of the world population lives, the sun shines throughout the year, causing minimal effect on the seasonal chronotype adaptation. Thus, it is important to assess whether individuals who live in the equatorial area are similarly affected by the variation in chronotype, and display the same trend as the sub-tropical inhabitants as shown by a previous meta-analysis [10].

In the present study, we examined the psychometry and chronotype of the college students in Indonesia, a country that lies precisely on the equator. Our site of research is situated at $1.3020^{\circ}$ North and $124.9134^{\circ}$ East proximate to the equator, thus providing a subject group with very distinctive characteristics of tropical inhabitants. This research aimed to 1) assess the associations between chronotypes with depression, anxiety, and stress (DAS) among the students in an Indonesian university by applying Depression, Anxiety, and Stress Scale (DASS) and Munich Chronotype questionnaires (MCTQ) as quantitative measurements for mental health and chronotype, respectively [11,12], and 2) explore the characteristics of those who lie at the extreme ends of the chronotype and psychometry. For the first aim, we hypothesized that chronotype is associated with DAS in Indonesian college students, whereas for the second aim, the author did not behold any prior assumption due to its exploratory nature.

\section{METHODS}

\section{Sample Selection}

The study was performed at the Public Health Department of Manado State University, Indonesia, and included all the undergraduate students from year 1 to year 4 at the time of research. Permission to carry out survey was sought from the appropriate university authority (Surat Izin No. 031/6-IKM). Informed consent was obtained from the participants. To ensure reliable and generalizable results, a total sampling technique was applied by distributing the questionnaires to all the students after a class session, apart from those that were unwilling to participate; no credits nor punishment were given for agreeing or refusing to participate in the study. For the qualitative study, a group of students at the extreme end of late chronotype with high depression scores were interviewed.

\section{Questionnaires}

To assess the chronotypes, we employed an Indonesian version of the MCTQ translated and validated in our center. We choose the MCTQ because it was shown to be sensitive in detecting chronotype shifts between high and low latitudes [13]. The MCTQ included questions on participants sleep duration and pattern during weekdays and weekends, and reported the sleep-deprivation corrected mid-sleep time at free days (MSFsc) and average sleep duration per week (SDw) as the main parameters. To assess the DAS level, a validated Indonesian version of DASS was used [14]. The DASS was chosen because it is reliable and easy to administer, especially in conjunction with MCTQ or other relatively long questionnaires, therefore preventing respondents' survey fatigue [11].

\section{Parameter Calculation}

Since there is a fundamental difference in the categorical interpretation of chronotype based on MSFsc between countries, geographical locations, and cultures, we decided to treat MSFsc as a linear scale, rather than categories (e.g. early, middle, or later phenotype). DASS were considered ordinal data as described [11]. MSFsc, the main parameter in determining the chronotype, is calculated by subtracting the mid-sleep time during free days from the sleep debt accumulated over a week, while SDw is the average of one week night's sleep duration.

\section{Qualitative Study}

We conducted an in-depth interview to delineate whether chronotype shift preceded depression symptoms or vice versa. We only interviewed the subjects who fell into the extreme ends of both spectra, i.e. the later chronotype and high depression scores $(n=5)$. Interviews were performed either face-to-face or by telephone upon appointment. The questions were prepared beforehand but kept open-ended to facilitate data gathering concerning the phenomenon. The main questions were: 1) how long he/she has been having a late chronotype ("sleep late");2) whether the "sleeping late" preceded the feeling of being depressed; 3) was there any major event that influenced the sleeping pattern or induced depression; and 4) the difference between activities done before sleeping when they started to sleep late compared to when they slept "normally."

\section{Statistics}

Quantitative data were entered into a master table, recording both the MCTQ and DASS scores, and the demographic characteristics. After removing incomplete entries $(n=8)$, the statistical analyses were performed using SPSS version 20.0 (IBM 
Corp., Armonk, NY, USA). As appropriate, chi-square, MannWhitney U-test, and Spearman's rank correlation tests were employed to calculate the statistical significance. Significance is set to be less than 0.05. Qualitative data such as the interview results were transcribed and analyzed qualitatively, by identifying common keywords and patterns among the respondents.

\section{RESULTS}

All the students $(n=501)$ agreed to participate and gave their consent to be included in the study. After the removal of incomplete questionnaires $(n=8)$, a representative group of 493 students (female $=251,50.91 \%$ ) was obtained and evaluated. The demographic characteristics are described in Table 1. After comparing the demography characteristics, DASS, and MCTQ parameters between sexes, we found differences in age, grades, as well as some habits such as coffee, smoke, and alcohol consumptions, which can be confounders in further analyses (Table 1). More importantly, we found a significant difference of MSFsc, the most important parameter of MCTQ, between males and females (Table 2). Based on these we further examined the relation between chronotype and DAS separately between males and females in subsequent analyses. Males had significantly later chronotypes compared to females (MSFsc 4:01 \pm 1:27 vs. 3:44 \pm $1: 19, \mathrm{p}=0.024$ by chi-square). In addition, a significant difference in stress level was also revealed $(p=0.002)$, where females perceived themselves as more stressed than males. On the other hand, there was no significant difference in sleep duration between sexes (6:43 $\pm 1: 22$ vs. $6: 45 \pm 1: 13, p=0.839)$.

In general, our results showed that DAS negatively correlated with sleep duration but positively correlated with chronotype
(Fig. 1). Statistical analyses showed that there is a small but significant correlation between depression score and MSFsc (Table 3), regardless of whether both sexes were analyzed together $(\mathrm{R}=0.133, \mathrm{p}=0.003)$ or separately: in males, the $\mathrm{R}=0.170$, while for females $\mathrm{R}=0.132$ ( $\mathrm{p}=0.008$ and 0.037 , respectively). This demonstrates that subjects with higher depression scores exhibited a later chronotype. Interestingly, the depression score negatively correlated with the SDw. Both males $(\mathrm{R}=-0.136, \mathrm{p}=0.035)$ and females $(\mathrm{R}=-0.215, \mathrm{p}=0.001)$ exhibited the same inverse correlation between depression scale and SDw. Thus, the respondents with depressive symptoms not only sleep later, but they also sleep shorter. In addition, there is also a significant correlation between $\mathrm{SDw}$ and female anxiety score $(\mathrm{R}=-0.155, \mathrm{p}=$ $0.016)$, and a weak correlation between overall group stress score with sleep duration $(\mathrm{R}=-0.096, \mathrm{p}=0.034)$.

To follow up on these findings, we conducted qualitative research by tracing and interviewing the subjects with high depression scores (severe to extremely severe) with later chronotype (within the fifth quintiles of the MSFsc). We initially aimed to identify the arrow of causality (e.g. whether the late chronotype predated depression or vice versa), the factors that contribute to their lateness (e.g. what activities were being done before or during bedtime), the chronotype of their parents or siblings, and the possible cause of their depressive symptoms, for those who were willing to share. Surprisingly, all the interviewed subjects (Table $4, \mathrm{n}=5$ ) were not aware that they scored high on the depression scale, and could not recall when was the first time they felt depressed. When asked about the potential causes of their depression, they picked some normative answers such as "I was being thoughtful (Indonesian: 'pikir-pikir,' a repetitive activity on thinking) about my grades" or "I am wondering about my future." These findings rendered our initial aims to reveal the

Table 1. The characteristics of the respondents

\begin{tabular}{|c|c|c|c|c|}
\hline Variable & Male $(n=242)$ & Female $(n=251)$ & All $(n=493)$ & $\mathrm{p}$-value \\
\hline Age & $19.34 \pm 1.23$ & $19.87 \pm 1.68$ & $19.61 \pm 1.49$ & $<0.001^{\dagger}$ \\
\hline GPA & $3.14 \pm 0.59$ & $3.33 \pm 0.34$ & $3.23 \pm 0.49$ & $0.003^{*}$ \\
\hline Cumulative GPA & $3.22 \pm 1.76$ & $3.33 \pm 0.33$ & $3.22 \pm 0.48$ & $<0.001^{\dagger}$ \\
\hline BMI & & & & 0.293 \\
\hline Underweight & $56(11.36)$ & $57(11.56)$ & $113(22.92)$ & \\
\hline Normal & $165(33.47)$ & $159(32.25)$ & $324(65.72)$ & \\
\hline Overweight & $19(3.85)$ & $33(6.69)$ & $52(10.55)$ & \\
\hline Obese & $2(0.41)$ & $2(0.41)$ & $4(0.81)$ & \\
\hline Smoking & $37(7.51)$ & $4(0.81)$ & $41(8.32)$ & $<0.001^{\dagger}$ \\
\hline Coffee (daily) & $88(17.85)$ & $46(9.33)$ & $134(27.18)$ & $<0.001^{\dagger}$ \\
\hline Alcohol (at least 1/week) & $32(6.49)$ & $3(0.61)$ & $35(7.10)$ & $<0.001^{\dagger}$ \\
\hline Sleeping pills consumption & 0 & 0 & 0 & - \\
\hline
\end{tabular}

Data are presented as mean \pm standard deviation or $\mathrm{n}(\%)$.

${ }^{*} \mathrm{p}<0.05 ;{ }^{\dagger} \mathrm{p}<0.001$, statistical tests are chi-square for categorical data and Mann-Whitney $\mathrm{U}$ test for numerical data.

GPA, grade point average; BMI, body mass index. 
Table 2. Depression, Anxiety, Stress Scale, and chronotype distribution based on sex

\begin{tabular}{|c|c|c|c|c|}
\hline Parameter & Male $(n=242)$ & Female $(n=251)$ & All $(\mathrm{n}=493)$ & p-value \\
\hline Depression & & & & 0.171 \\
\hline Normal & $188(52)$ & $176(48)$ & 364 & \\
\hline Mild & $26(49)$ & $27(51)$ & 53 & \\
\hline Moderate & $21(36)$ & $38(64)$ & 59 & \\
\hline Severe & $7(44)$ & $9(56)$ & 16 & \\
\hline Extremely severe & $0(0)$ & $1(100)$ & 1 & \\
\hline Score & $6.33 \pm 5.394$ & $7.60 \pm 5.812$ & $6.97 \pm 5.641$ & \\
\hline Anxiety & & & & 0.170 \\
\hline Normal & $71(56)$ & $56(44)$ & 127 & \\
\hline Mild & $67(52)$ & $62(48)$ & 129 & \\
\hline Moderate & $67(43)$ & $89(57)$ & 156 & \\
\hline Severe & $28(49)$ & $29(51)$ & 57 & \\
\hline Extremely severe & $9(37)$ & $15(63)$ & 24 & \\
\hline Score & $9.34 \pm 5.402$ & $10.38 \pm 5.289$ & $9.87 \pm 5.365$ & \\
\hline Stress & & & & $0.002^{\dagger}$ \\
\hline Normal & $125(58)$ & $90(42)$ & 215 & \\
\hline Mild & $92(41)$ & $130(59)$ & 222 & \\
\hline Moderate & $24(47)$ & $27(53)$ & 51 & \\
\hline Severe & $0(0)$ & $4(100)$ & 4 & \\
\hline Extremely severe & $1(100)$ & $0(0)$ & 1 & \\
\hline Score & $10.94 \pm 6.487$ & $12.65 \pm 5.585$ & $11.81 \pm 6.099$ & \\
\hline MSFsc (local time) & $4: 01 \pm 1: 27$ & $3: 44 \pm 1: 19$ & $3: 52 \pm 1: 23$ & $0.024^{*}$ \\
\hline Sleep duration (hr:min) & $6: 43 \pm 1: 22$ & $6: 45 \pm 1: 13$ & $6: 44 \pm 1: 17$ & 0.839 \\
\hline
\end{tabular}

Data are presented as $\mathrm{n}(\%)$ or mean \pm standard deviation.

${ }^{*} \mathrm{p}<0.05 ;{ }^{\dagger} \mathrm{p}<0.01$, statistical tests are chi-square for categorical data and Mann-Whitney $\mathrm{U}$ test for numerical data.

MSFsc, sleep-deprivation corrected mid-sleep time at free days.

sequence of events and the causality arrow unreachable. Nevertheless, the rest of the interview acted as an explorative study about related properties of chronotype and depression. The most consistent item answered by the subjects is the activities that prevented them from sleeping early: all of them were engaged in different activities on their smartphones; social media, watching online videos, or games. All of them mentioned that the habit was formed during high school (approximately 3-4 years before this research), and it was currently almost impossible to go sleep without playing with their smartphones. While they all wanted to change their chronotype, they find it not urgent.

\section{DISCUSSION}

\section{A Consistent Correlation Between Chronotype and Depressive Symptoms Across Latitudes as Shown by DASS}

While there are many studies on mental health and chronotype, data from tropical and equatorial countries are lacking; to the best of our knowledge, so far, the comparable reports from the tropical areas came from limited sources such as Brazil and Taiwan, in which the chronotype and depressive symptoms were the main parameters [7,15-17]. Since the daylight duration is constant throughout the year in the equatorial area, the effect of seasonal sunshine deprivation on the mood may be negligible, thus rendering a very different pattern of the effects on mental health compared to the subtropical area. In the present research study, we replicated the findings of the previous studies, showing that even in the environment where the sun shines constantly, human chronotype varies, and more importantly, it correlates with mental health parameters, in particular with depressive symptoms. We observed a significant correlation between chronotypes (MSFsc and SDw) and depression score in both sexes, a phenomenon that has been well documented in studies on other subtropical areas [18-22]. It has been well established that seasonal affective disorders are related to the circadian cues from the sunlight, and many depression symptom outbreaks occur during winter, hence the term 'winter blue' [23]. The mood swing throughout the year may be a confounding factor in ex- 


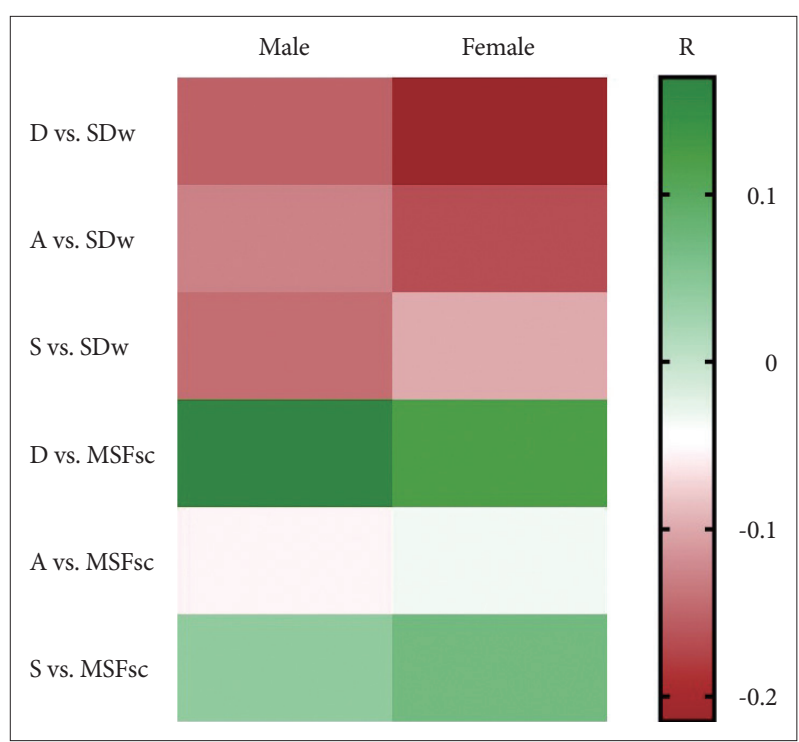

Fig. 1. The heatmap of $R$ values (Spearman's rank correlation) between each parameter in Depression, Anxiety, and Stress Scale and Munich Chronotype questionnaires. There is a negative correlation between DAS and sleep duration, and a positive correlation between DAS and MSFsc. Statistical calculations revealed significant correlations as described in Table 3. D, depression score; SDw, average sleep duration per week; A, anxiety score; S, stress score; MSFsc, sleep-deprivation corrected midsleep time at free days; DAS, depression, anxiety, and stress.

Table 3. The correlation matrix between chronotype and Depression, Anxiety, and Stress Scale

\begin{tabular}{lcccccccc}
\hline & \multicolumn{2}{c}{ Male } & & \multicolumn{2}{c}{ Female } & & \multicolumn{2}{c}{ Male \pm female } \\
\cline { 2 - 3 } & $\mathrm{R}$ & $\mathrm{p}$ & & $\mathrm{R}$ & $\mathrm{p}$ & & $\mathrm{R}$ & $\mathrm{p}$ \\
\hline D vs. SDw & -0.136 & $0.035^{*}$ & & -0.215 & $0.001^{\dagger}$ & -0.177 & $0.001^{\dagger}$ \\
D vs. MSFsc & 0.170 & $0.008^{\dagger}$ & & 0.132 & $0.037^{*}$ & 0.133 & $0.003^{\dagger}$ \\
A vs. SDw & -0.105 & 0.105 & & -0.155 & $0.016^{*}$ & -0.122 & $0.007^{\dagger}$ \\
A vs. MSFsc & -0.006 & 0.920 & & 0.021 & 0.737 & & -0.011 & 0.810 \\
S vs. SDw & -0.125 & 0.052 & & -0.069 & 0.278 & & -0.096 & $0.034^{*}$ \\
S vs. MSFsc & 0.067 & 0.299 & & 0.092 & 0.146 & 0.061 & 0.180 \\
\hline
\end{tabular}

${ }^{*} \mathrm{p}<0.05 ;{ }^{\dagger} \mathrm{p}<0.01$, Spearman's rank correlation.

$\mathrm{D}$, depression score; SDw, average sleep duration per week; MSFsc, sleep-deprivation corrected mid-sleep time at free days; A, anxiety score; $\mathrm{S}$, stress score. amining the depression symptoms, especially when using selfreported questionnaires such as DASS. Therefore, we thought that replicating such studies in an equatorial area may diminish the confounder and provide extended knowledge on depressive symptoms in relation to the other variables. Indeed, our current findings add to the available body of knowledge that, in the equatorial area where the seasonal daylight fluctuation is negligible, the correlation between chronotype and depression is preserved. It is notable that although there are strong correlations between DASS sections ( $\mathrm{D}$ vs. A: $\mathrm{R}=0.660, \mathrm{p}<0.001$; $\mathrm{D}$ vs. S: $\mathrm{R}=0.675, \mathrm{p}<0.001$, A vs. $\mathrm{S}: \mathrm{R}=0.684, \mathrm{p}<0.001$ ), the correlation with the chronotype is mostly existent in the depression section, which emphasized the validity of the currently used questionnaires in distinguishing subtypes of mental health symptoms.

There was a striking difference in the SDw between the present study and the previous studies. We found that our respondents had SDw of 6:44 \pm 1:17 hours, lower than that reported in previous research studies from sub-tropical areas (multinational average around 7:48 hrs). However, on a closer examination, people from Asian countries have shorter SDw. Peltzer and Pengpid [24] reported a mean sleep duration of 6.59 hrs (range: 6.49-6.68 hrs) for Indonesia, comparable to Singapore (6.67 hrs), the Philippines (6.53 hrs), and South East Asia in general (6.82 hrs; range 6.78-6.87 hrs). In addition, Romadhon and Abdussalaam [25] reported that sleep duration in the Moslem community in Indonesia is around 5:58 to 6:15 hours with substantial variation across ages, thus adding a layer of complexity in determining a nationwide SDw. However, on top of this unique relatively short SDw, the effect of chronotype on depression symptoms is preserved.

\section{Females Proneness to Stress}

Across different cultures and countries, females have consistently been shown to be more likely to develop depression and anxiety disorders [26-28]. Our results also showed that female participants consistently scored higher in all parameters of DASSs as measured by DASS. The cause of this skewness across the literature has never been satisfactorily explained. Some explanation comes from socioeconomic factors [28] and the observation that females are more vulnerable to past adverse experi-

Table 4. The characteristics of the respondents included in the qualitative interview

\begin{tabular}{ccccccccccccc}
\hline Sex & GPA & CGPA & BMI & $\begin{array}{c}\text { SDw } \\
(\mathrm{hr}: \mathrm{min})\end{array}$ & $\begin{array}{c}\text { MSFsc } \\
(\mathrm{hr}: \mathrm{min})\end{array}$ & $\mathrm{D}$ & $\mathrm{A}$ & $\mathrm{S}$ & Smoking & Coffee & Alcohol \\
\hline F & 2.50 & 3.00 & Normal & $7: 51$ & $5: 30$ & Extremely severe & Extremely severe & Severe & $\mathrm{N}$ & $\mathrm{Y}$ & $\mathrm{N}$ \\
$\mathrm{M}$ & 2.80 & 2.75 & Normal & $6: 08$ & $6: 04$ & Severe & Extremely severe & Moderate & $\mathrm{Y}$ & $\mathrm{Y}$ & $\mathrm{Y}$ \\
$\mathrm{F}$ & 2.87 & 2.87 & Normal & $6: 17$ & $5: 08$ & Severe & Extremely severe & Moderate & $\mathrm{N}$ & $\mathrm{N}$ & $\mathrm{N}$ \\
$\mathrm{F}$ & 4.00 & 3.80 & Normal & $6: 17$ & $5: 08$ & Severe & Severe & Moderate & $\mathrm{N}$ & $\mathrm{N}$ & $\mathrm{N}$ \\
$\mathrm{M}$ & 2.00 & 2.00 & Normal & $7: 42$ & $7: 00$ & Severe & Severe & Moderate & $\mathrm{N}$ & $\mathrm{N}$ & $\mathrm{N}$ \\
\hline
\end{tabular}

GPA, grade point average; CGPA, cumulative grade point average; BMI, body mass index; SDw, average sleep duration per week; MSFsc, sleep-deprivation corrected mid-sleep time at free days; D, depression score; A, anxiety score; S, stress score. 
ences [29]. Notably, our data showed that females relatively possess an earlier chronotype than males, despite having the same sleep duration. We would address this chronotype difference based on previous observations that females tend to sleep and wake up earlier than males [30,31] and the effect of testosterone in shaping late chronotype among males [32]. Thus, there seems to be an intrinsic uniqueness of self-perception of being depressed, anxious and stressed among females that cannot be explained by chronotype alone. Further research is necessary to confirm this. Some prospective research directions include providing different scoring criteria for women or tailoring specialized questionnaires based on gender.

\section{Qualitative Research: Subclinical Depression?}

Based on our findings, the respondents who scored high on the depression scale were unaware of being at the extreme severity scale during the qualitative analysis interview. Since DASS measures the symptoms of depression-instead of acting as a diagnostic tool as mentioned in the Diagnostic and Statistical Manual of Mental Disorders, there is a possibility that this could result in the inaccuracy of the self-reporting process. However, as discussed above, given the intrinsic validity of the DASS questionnaire between sections, it is unlikely that this unawareness could result from false-positive reporting. Instead, we would propose that subclinical depression may be imminent on these subjects, which is a predictor of future major depressive disorder [33,34]. In addition, the fact that these respondents are on the extreme late chronotype, as supported by previous research, places them at a high risk of developing depression [18-20,22].

\section{Smartphones as a Source of Artificial Light and Potential Risk of Health-Related Problems in the Future}

While our qualitative study is not sufficient to conclude that smartphone use is responsible for chronotype lateness and depression, it is well known that gadgets such as smartphones or tablets emit blue light that disrupts the circadian system putatively by interfering with the melatonin secretion [35]. Eventually, this lead to an increased incidence of a wide range of psychiatric and somatic disorders [36]. Sadly, gadget use is capable of inducing habituation and addictive behavior especially among youths and undergraduate students $[37,38]$. Furthermore, gadget use, as many other types of addiction, can provide a dopamine release in the brain reward system, thus providing a temporal release of stress, anxiety, or even subclinical depression as discussed above. In combination, this can lead to a vicious cycle of addiction-depression-coping that may need to be professionally intervened. This highlights the need for an initiative for controlling such behaviors and more effort to increase the student's awareness of the imminence of gadget use. It has also been demonstrated that chronotype disturbance is related to a wide range of somatic diseases such as cancer, cardiovascular, and meta- bolic disorders [39], thus adding more reasons to include circadian rhythm management as a preventive measure against future pathologies.

\section{Current Limitations and Future Research}

Our present findings highlight the positive correlation between depression severity and chronotype, as well as a negative correlation between depression and sleep duration. While these three variables are not necessarily dependent, late-onset and short duration of sleep may reflect a low sleep quality. Thus, one of the immediate follow-up to this finding, and may be a future research topic, would be to evaluate whether depression indeed correlates with sleep quality. In addition, in the future, it is important to incorporate the circadian biomarker (e.g. plasma melatonin) examination in the subjects with extreme chronotype and perform experimental corrective studies such as assistedchronotype restoration. While the present research study involved a relatively small population from a specific, homogenous group (college students) it may represent the societies in the equatorial area. However, further replication studies would be necessary to test the generalizability.

\section{Conclusion}

There is a correlation between chronotype and depression severity. Subjects with later chronotype tend to have higher depression score without being necessarily aware of it. The use of smartphones during or before bedtime may contribute to the shifting of the chronotype towards a later chronotype.

\section{Availability of Data and Material}

The datasets generated or analyzed during the study are available from the corresponding author on reasonable request.

\section{Author Contributions}

Conceptualization: Supit A, Mamuaja P. Data curation: Gosal M. Formal analysis: Gosal M, Mamuaja P. Investigation: Supit A, Mamuaja P. Methodology: Supit A, Mamuaja P. Project administration: Paturusi A. Resources: Supit A. Software: Supit A. Supervision: Paturusi A. Validation: Gosal M, Supit A. Visualization: Supit A. Writing_original draft: Supit A, Kumaat S. Writing-review \& editing: Supit A.

\section{Conflicts of Interest}

The authors have no potential conflicts of interest to disclose.

\section{Funding Statement}

None.

\section{Acknowledgements}

The authors would like to thank the Head of Public Health Department and the Dean of the Faculty of Sport Science Manado State University for the permission to conduct the research on the campus site.

\section{REFERENCES}

1. Bell-Pedersen D, Cassone VM, Earnest DJ, Golden SS, Hardin PE, Thomas TL, et al. Circadian rhythms from multiple oscillators: lessons from diverse organisms. Nat Rev Genet 2005;6:544-56. 
2. Li S, Shui K, Zhang Y, Lv Y, Deng W, Ullah S, et al. CGDB: a database of circadian genes in eukaryotes. Nucleic Acids Res 2017;45:D397-403.

3. Zhang R, Lahens NF, Ballance HI, Hughes ME, Hogenesch JB. A circadian gene expression atlas in mammals: implications for biology and medicine. Proc Natl Acad Sci U S A 2014;111:16219-24.

4. Ko CH, Takahashi JS. Molecular components of the mammalian circadian clock. Hum Mol Genet 2006;15:R271-7.

5. Blume C, Garbazza C, Spitschan M. Effects of light on human circadian rhythms, sleep and mood. Somnologie (Berl) 2019;23:147-56.

6. Romo-Nava F, Tafoya SA, Gutiérrez-Soriano J, Osorio Y, Carriedo P, Ocampo B, et al. The association between chronotype and perceived academic stress to depression in medical students. Chronobiol Int 2016; 33:1359-68.

7. Levandovski R, Dantas G, Fernandes LC, Caumo W, Torres I, Roenneberg T, et al. Depression scores associate with chronotype and social jetlag in a rural population. Chronobiol Int 2011;28:771-8.

8. Park H, Lee HK, Lee K. Chronotype and suicide: the mediating effect of depressive symptoms. Psychiatry Res 2018;269:316-20.

9. Selvi Y, Aydin A, Boysan M, Atli A, Agargun MY, Besiroglu L. Associations between chronotype, sleep quality, suicidality, and depressive symptoms in patients with major depression and healthy controls. Chronobiol Int 2010;27:1813-28.

10. Au J, Reece J. The relationship between chronotype and depressive symptoms: a meta-analysis. J Affect Disord 2017;218:93-104.

11. Norton PJ. Depression anxiety and stress scales (DASS-21): psychometric analysis across four racial groups. Anxiety Stress Coping 2007; 20:253-65

12. Roenneberg T, Kuehnle T, Juda M, Kantermann T, Allebrandt K, Gordijn M, et al. Epidemiology of the human circadian clock. Sleep Med Rev 2007;11:429-38.

13. Miguel M, Oliveira VC, Pereira D, Pedrazzoli M. Detecting chronotype differences associated to latitude: a comparison between Horne--Östberg and Munich Chronotype questionnaires. Ann Hum Biol 2014;41: 107-10.

14. Psychology Foundation of Australia. Depression anxiety stress scales (DASS) [cited 2021 Aug 1]. Available from: http://www2.psy.unsw. edu.au/dass/.

15. Hidalgo MP, Caumo W, Posser M, Coccaro SB, Camozzato AL, Chaves ML. Relationship between depressive mood and chronotype in healthy subjects. Psychiatry Clin Neurosci 2009;63:283-90.

16. Hirata FC, Lima MC, de Bruin VM, Nóbrega PR, Wenceslau GP, de Bruin PF. Depression in medical school: the influence of morningnesseveningness. Chronobiol Int 2007;24:939-46.

17. Hsu CY, Gau SS, Shang CY, Chiu YN, Lee MB. Associations between chronotypes, psychopathology, and personality among incoming college students. Chronobiol Int 2012;29:491-501.

18. Chelminski I, Ferraro FR, Petros TV, Plaud JJ. An analysis of the "eveningness-morningness" dimension in "depressive" college students. $J$ Affect Disord 1999;52:19-29.

19. Furusawa M, Okubo Y, Kuroda R, Umekage T, Nagashima S, Suwazono Y. Relationship between morningness-eveningness typology and cumulative fatigue or depression among Japanese male workers. Ind Health 2015;53:361-7.

20. Hasler BP, Allen JJ, Sbarra DA, Bootzin RR, Bernert RA. Morningnesseveningness and depression: preliminary evidence for the role of the behavioral activation system and positive affect. Psychiatry Res 2010; 176:166-73.
21. Kim SJ, Lee YJ, Kim H, Cho IH, Lee JY, Cho SJ. Age as a moderator of the association between depressive symptoms and morningness-eveningness. J Psychosom Res 2010;68:159-64.

22. Oginska H, Oginska-Bruchal K. Chronotype and personality factors of predisposition to seasonal affective disorder. Chronobiol Int 2014;31: 523-31.

23. Melrose S. Seasonal affective disorder: an overview of assessment and treatment approaches. Depress Res Treat 2015;2015:178564.

24. Peltzer K, Pengpid S. Sleep duration and health correlates among university students in 26 countries. Psychol Health Med 2016;21:208-20.

25. Romadhon YA, Abdussalaam AH. Chronotype study in Moslem community in Indonesia. Proceedings of the 9th URECOL 2019 Tema: Aktualisasi Nilai Kearifan Lokal berbasis Riset pada Era Revolusi Industri 4.0; 2019 Mar 9; Purworejo, Indonesia: URECOL; 2019. p.38397.

26. Sagud M, Hotujac Lj, Mihaljević-Peles A, Jakovljević M. Gender differences in depression. Coll Antropol 2002;26:149-57.

27. Frank E, Carpenter LL, Kupfer DJ. Sex differences in recurrent depression: are there any that are significant? Am J Psychiatry 1988;145:41-5.

28. Gutiérrez-Lobos K, Wölfl G, Scherer M, Anderer P, Schmidl-Mohl B. The gender gap in depression reconsidered: the influence of marital and employment status on the female/male ratio of treated incidence rates. Soc Psychiatry Psychiatr Epidemiol 2000;35:202-10.

29. Piccinelli M, Wilkinson G. Gender differences in depression. Critical review. Br J Psychiatry 2000;177:486-92.

30. Duarte LL, Menna-Barreto L, Miguel MA, Louzada F, Araújo J, Alam $\mathrm{M}$, et al. Chronotype ontogeny related to gender. Braz J Med Biol Res 2014;47:316-20.

31. Lehnkering H, Siegmund R. Influence of chronotype, season, and sex of subject on sleep behavior of young adults. Chronobiol Int 2007;24: 875-88.

32. Jankowski KS, Fajkowska M, Domaradzka E, Wytykowska A. Chronotype, social jetlag and sleep loss in relation to sex steroids. Psychoneuroendocrinology 2019;108:87-93.

33. Karsten J, Hartman CA, Smit JH, Zitman FG, Beekman AT, Cuijpers P, et al. Psychiatric history and subthreshold symptoms as predictors of the occurrence of depressive or anxiety disorder within 2 years. $\mathrm{Br} \mathrm{J}$ Psychiatry 2011;198:206-12.

34. Ji J. Distinguishing subclinical (subthreshold) depression from the residual symptoms of major depression. Shanghai Arch Psychiatry 2012; 24:288-9.

35. Oh JH, Yoo H, Park HK, Do YR. Analysis of circadian properties and healthy levels of blue light from smartphones at night. Sci Rep 2015; 5:11325.

36. Stevens RG, Brainard GC, Blask DE, Lockley SW, Motta ME. Adverse health effects of nighttime lighting: comments on American Medical Association policy statement. Am J Prev Med 2013;45:343-6.

37. Kumar A, Sherkhane M. Assessment of gadgets addiction and its impact on health among undergraduates. Int J Community Med Public Health 2018;5:3624-8.

38. Jamir L, Duggal M, Nehra R, Singh P, Grover S. Epidemiology of technology addiction among school students in rural India. Asian J Psychiatr 2019;40:30-8.

39. Yu JH, Yun CH, Ahn JH, Suh S, Cho HJ, Lee SK, et al. Evening chronotype is associated with metabolic disorders and body composition in middle-aged adults. J Clin Endocrinol Metab 2015;100:1494-502. 